\title{
POTENSI PENGEMBANGAN EKOWISATA DI NAGARI KOTOBARU, KECAMATAN X KOTO, KABUPATEN TANAH DATAR SUMATERA BARAT
}

\author{
Firdaus dan Rio Tutri \\ Prodi Pendidikan Sosiologi, Sekolah Tinggi Keguruan dan Ilmu Pendidikan \\ (STKIP) PGRI Sumatera Barat \\ email: firdaus@stkip-pgri-sumbar.ac.id dan rio_tutri@yahoo.co.id
}

\begin{abstract}
In recent years, tourism has been the important economic and social activities in the world. Tourism studies that showed the impacts of tourism activity to economic countries were significant. In Indonesia, the developing of tourism conducted as primary sector to support the other economic sectors, in particularly in both trade and service. The Indonesian tourism development primary is nature and culture. This research aimed to analyze and describe ecotourism potency of Nagari Kotobaru, Kabupaten Tanah Datar as the door to summit of Merapi Mountain in West Sumatera. This research conducted with qualitative approach in 2016. Data was collected with observation, depth interview and document study. The potency ecotourism development was analyzed through SWOT analysis. The result showed that the Nagari Kotobaru strength was in poor and there were some weakness too. Although, Nagari Kotobaru have potencies to be created as an ecotourism area without serious threat. Based on the SWOT analysis, the mode of ecotourism that would be applied to Nagari Kotobari was ecotourism community type.
\end{abstract}

Keywords: Ecotourism of Nagari; SWOT Analysis; Tourism.

\begin{abstract}
ABSTRAK
Pariwisata telah menjadi aktivitas sosial dan ekonomi penting di berbagai belahan dunia dalam beberapa dekade terakhir. Kajian-kajian tentang pariwisata menunjukkan bahwa aktivitas pariwisata telah mampu menyumbang perekonomian negara. Pembangunan pariwisata di Indonesia diarahkan sebagai sektor andalan yang mampu menggerakkan berbagai aktivitas ekonomi di sektor lain, terutama perdagangan dan jasa. Pengembangan wisata Indonesia diarahkan pada potensi alam dan budaya yang dimiliki. Penelitian ini bertujuan untuk mendeskripsikan potensi pengembangan ekowisata di Nagari Kotobaru, Kab. Tanah Datar Sumatera Barat yang merupakan pintu masuk ke kawasan Gunung Merapi. Penelitian dilakukan secara kualitatif pada tahun 2016. Data dikumpulkan melalui observasi, wawancara mendalam dan studi dokumen. Potensi pengembangan ekowisata di Nagari Kotobaru dilakukan dengan menggunakan analisis SWOT. Dari hasil analisis SWOT, diketahui bahwa kekuatan Nagari Kotobaru sebagai kawasan ekowisata masih minim dan juga terdapat beberapa kelemahan. Namun sebaliknya, Nagari Kotobaru memiliki banyak potensi yang berpeluang untuk dikembangkan menjadi kawasan ekowisata dan juga tidak ada ancaman berarti. Berdasarkan analisis SWOT tersebut, maka pola ekowisata yang dapat dikembangkan di Nagari Kotobaru adalah ekowisata tipe masyarakat.
\end{abstract}

Kata Kunci: Analisis SWOT; Ekowisata Nagari; Pariwisata. 


\section{PENGANTAR}

Pariwisata merupakan manifestasi gejala naluri manusia sejak purbakala, yaitu hasrat untuk mengadakan perjalanan (Syamsuridjal \& Kaelany, 1996). Hanya saja, sampai saat ini belum ada satu kesamaan pendapat tentang batasan pariwisata dan belum ada kesepakatan secara akademis mengenai apa itu wisatawan dan pariwisata (Pitana \& Gayatri, 2005). Ketiadaan kesamaan membuat tidak adanya batasan yang berlaku secara universal tentang pariwisata yang dapat diterima semua orang. Masing-masing pakar memberikan batasan sesuai pandangannya sendiri dan sesuai dengan latar belakang pendidikan dan pengalaman sendiri pula (Yoety, 2008). Sebaliknya, pengaruh pariwisata telah banyak dirasakan, terutama di sektor ekonomi dan sosial.

Kontribusi pariwisata terhadap ekonomi dan sosial yang signifikan dalam beberapa dasawarsa terakhir di banyak negara (berkembang), wilayah, masyarakat, investor menaruh perhatian khusus pada dunia pariwisata dan bahkan terjun melibatkan diri dalam dunia Pariwisata. Hal ini antara lain terlihat dari banyaknya program pengembangan pariwisata di berbagai negara di belahan dunia (Abya, Khalili, Ebrahimi, \& Movahed, 2015; Spillane, 1987). Di Indonesia, pariwisata yang berlangsung sejak zaman kolonial sudah mendapat perhatian sebagai prioritas pembangunan sejak Orde Baru (Picard, 2005; Spillane, 1987). Kebijakan pengembangan kepariwisataan Indonesia dituangkan dalam Instruksi Presiden (Inpres) No. 9 tahun 1969. Kebijakan tersebut dilatarbelakangi oleh perkembangan kepariwisataan Indonesia yang cenderung meningkat positif dan besarnya potensi yang dimiliki untuk pengembangan pariwisata Indonesia (Spillane, 1987; Yoety, 2008). Tujuan pengembangan kepariwisataan adalah untuk kepentingan ekonomi, sosial, budaya, dan kelestarian alam (Indonesia, 1969).

Sejak menjadi prioritas dan perhatian pembangunan, perkembangan pariwisata Indonesia mengalami pertumbuhan yang positif dan menyumbang secara sosial dan ekonomi. Pertumbuhan pariwisata Indonesia menyumbang terhadap pendapatan nilai tukar valuta asing, penerimaan devisa akibat adanya konsumsi wisatawan, dan pembangunan infrastruktur pariwisata yang turut dinikmati oleh masyarakat lokal. Beberapa destinasi pariwisata juga menjadi generator pemberdayaan perekonomian masyarakat lokal (Kurniawati, 2013). Pariwisata memberikan lapangan kerja bagi masyarakat di daerah tujuan wisata, di mana satu dari delapan pekerja di dunia ini kehidupannya tergantunglangsung atau tidak langsung- dari pariwisata (Pitana \& Gayatri, 2005).

Bersamaan dengan tren perkembangan pariwisata dunia dari mass tourisme ke niche tourisme (Yoety, 2006), kebijakan pengembangan pariwisata nasional diarahkan ke pariwisata minat khusus dan menjadikan ekowisata sebagai salah satu dari tujuh fokus pengembangan kepariwisataan Indonesia (Kementrian Pariwisata, 2015). Seiring dengan pengembangan ekowisata, upaya melibatkan masyarakat sebagai pelaku utama mulai tumbuh dengan baik dan telah memberikan manfaat sosial dan ekonomi bagi masyarakat. Di kampung Batusuhunan Sukabumi, ekowisata yang baru dikembangkan tiga tahun telah mampu memberikan perubahan positif terutama pada aspek ekologi dan sosial masyarakat. Tingkat kesadaran menjaga lingkungan dan gaya hidup ramah lingkungan meningkat di Desa Batusuhunan sejak adanya ekowisata (Hijriati \& Mardiana, 2014). Di Jambi, pengembangan Desa Wisata Sambi telah memberikan kontribusi ekonomi dengan menyumbang terhadap peningkatan pendapatan masyarakat serta munculnya peluang usaha baru (Sudarmadji \& Darmanto, 2014).

Pengalaman-pengalaman positif pengembangan ekowisata tersebut harus juga dikembangkan ke kawasan-kawasan lain yang dinilai potensial sebagai kawasan ekowisata bersamaan dengan geliat perkembangan pariwisata di Indonesia yang positif. Data statistik BPS menunjukkan perkembangan jumlah wisatawan yang berkunjung ke Indonesia terus meningkat dari tahun ke tahun, begitu juga dengan penerimaan 
devisa. Perkembangan positif kunjungan dan penerimaan devisa tersebut dapat dilihat enam tahun terakhir sebagaimana tergambar dalam tabel 1. Selain itu, selama Januari-Mei 2016 jumlah kunjungan wisatawan mancanegara ke Indonesia mencapai 4,43 juta kunjungan atau naik 7,48 persen dibandingkan dengan jumlah kunjungan pada periode yang sama tahun 2015 yang tercatat sebanyak 4,13 juta kunjungan (BPS, 2016).

Tabel 1 Data Kunjungan Wisatawan Mancanegara ke Indonesia dan Penerimaan Devisa 2010-2015

\begin{tabular}{l|l|l|l}
\hline No & Tahun & $\begin{array}{c}\text { Jumlah } \\
\text { Pengunjung } \\
\text { (Org) }\end{array}$ & $\begin{array}{c}\text { Penerimaan } \\
\text { Devisa (Juta US\$) }\end{array}$ \\
\hline 1 & 2010 & 7.002 .944 & 7.603 .45 \\
\hline 2 & 2011 & 7.649 .731 & 8.554 .39 \\
\hline 3 & 2012 & 8.044 .462 & 9.120 .89 \\
\hline 4 & 2013 & 8.802 .129 & 10.054 .15 \\
\hline 5 & 2014 & 9.435 .411 & 11.166 .13 \\
\hline 6 & 2015 & 9.708 .897 & - \\
\hline
\end{tabular}

Sumber: Diolah dari Data dan Berita Resmi BPS

Tren positif perkembangan pariwisata secara nasional ini harus disikapi dengan upaya ke arah pengembangan destinasi wisata baru berbasis alam sesuai dengan prinsip pembangunan berkelanjutan. Sebagai bagian dari kawasan strategis pengembangan wisata Indonesia wilayah barat, Nagari Kotobaru, Kecamatan X Koto, Sumatera Barat potensial dikembangkan sebagai kawasan ekowisata (Nagari merupakan sistem pemerintahan terendah di Sumatera Barat). Potensi tersebut didasarkan peran Nagari Kotobaru sebagai pintu masuk ke puncak Gunung Merapi, suasana alam yang dimiliki, dan aktivitas pertanian masyarakat di nagari. Tulisan hasil studi lapangan ini akan mendeskripsikan potensi pengembangan ekowisata di Nagari Kotobaru, Kabupaten Tanah Datar, Sumatera Barat. Tulisan ini mencakup potensi yang dimiliki oleh nagari untuk dikembangkan sebagai kawasan ekowista dan analisis peluang dan tantangan pengembangan nagari sebagai kawasan ekowisata. Analisis pengembangan dilakukan dengan kerangka analisis SWOT.
Artikel ini ditulis dari hasil penelitian kualitatif yang dilakukan pada tahun 2016 dan didanai oleh DIKTI dalam skema penelitian dosen pemula. Penelitian lapangan dilakukan di Nagari Kotobaru, Kecamatan X Koto, Kabupaten Tanah Datar. Proses pengumpulan data dilakukan melalui observasi, wawancara mendalam, dan studi dokumen. Observasi dilakukan selama proses penelitian untuk mendapatkan gambaran tentang kondisi alam dan aktivitas harian masyarakat petani Nagari Kotobaru. Observasi terutama dilakukan di Jorong Subarang yang merupakan pintu masuk ke Gunung Merapi dan pusat pertanian holtikultura.

Wawancara mendalam dilakukan dengan pemerintah nagari, tokoh masyarakat, dan masyarakat nagari yang sedang melakukan aktivitas di ladang mereka. Wawancara mendalam dengan pemerintah nagari dilakukan untuk mendapatkan gambaran tentang kebijakan, tata kelola, pelaksanaan dan perkembangan kegiatan wisata di tingkat nagari, terutama yang berhubungan dengan pintu masuk kawasan Gunung Merapi. Wawancara dengan tokoh masyarakat ditujukan untuk trianggulasi terhadap data wawancara dengan pemerintah nagari, sekaligus mendapatkan pandangan mereka terhadap pengembangan ekowisata. Sementara wawancara dengan masyarakat, ditujukan untuk trianggulasi data wawancara pemerintah dan tokoh, sekaligus menggali kesiapan mereka sebagai pelaku ekowisata. Total keseluruhan informan yang diwawancarai dalam penelitian ini adalah 15 orang. Studi dokumen dilakukan dengan mempelajari dokumen-dokumen resmi dari pemerintahan nagari dan kabupaten sesuai dengan kebutuhan penelitian.

Proses analisis data dilakukan dengan menggunakan tahapan reduksi/ferivikasi data, display data, dan interpretasi data untuk kemudian dibuat kesimpulan (Miles \& Huberman, 1992). Hasil analisis data disajikan dalam artikel ini dalam bentuk narasi dan tabel sesuai dengan sistematika penulisan. Dokumen hasil observasi (dalam bentuk foto) yang dinilai penting dijadikan satu kesatuan dalam narasi artikel untuk menguatkan data lapangan. 


\section{PEMBAHASAN}

\section{Nagari Kotobaru: Etalase Kabupaten Tanah Datar}

Berada di ketinggian 1050-1300 mdpl, Nagari Kotobaru dibelah oleh jalan propinsi yang menghubungkan Kota Padang dan Bukittinggi. Dari Kota Padang (Ibukota Sumatera Barat) ke Nagari Kotobaru hanya berjarak $70 \mathrm{Km}$ dari arah selatan. Sebelum sampai ke Nagari Kotobaru, perjalanan dari Kota Padang akan melewati Kota Padang Panjang, sebuah kota kecil bersuhu sejuk dengan curah hujan tinggi. Nagari Kotobaru persis berada di antara dua kota di dataran tinggi Sumatera Barat, yaitu Kota Bukittinggi di sebelah utara dan kota Padang Panjang di sebelah selatan. Jarak dari Nagari Kotobaru ke dua kota ini hanya $\pm 10 \mathrm{~km}$. Selain letaknya di perlintasan, nagari berhawa sejuk dengan suhu rata-rata $21^{\circ} \mathrm{C}$ ini juga diapit oleh Gunung Merapi di sisi Timur dan Gunung Singgalang di sisi Barat. Alam pegunungan dengan curah hujan $2500-4000 \mathrm{~mm} /$ tahun sangat khas terasa sepanjang hari. Suasana dingin sangat terasa pada malam hari, di mana suhu lebih dingin dan rata-rata mencapai di bawah $18^{\circ} \mathrm{C}$.

Secara administratif, Nagari Kotobaru merupakan bagian terluar dari Kabupaten Tanah Datar yang berbatasan langsung dengan Kabupaten Agam di sebelah utara. Nagari dengan luas 1.000 ha ini dihuni oleh 2.479 orang penduduk yang tersebar di Jorong Koto (200 ha) sebanyak 1.430 orang dan di Jorong Subarang (250 ha) sebanyak 1.049 orang dengan jumlah total 671 KK. Seluas 550 ha lahan Nagari Kotobaru berstatus hutan lindung. Secara administratif Nagari Kotobaru di sebalah utara berbatas dengan Nagari Pandai Sikek, sebelah selatan dengan nagari Kayu Tanduak dan Nagari Aia Angek, sebelah barat Nagari Pandai Sikek dan sebelah timur dengan hutan negara.

Mayoritas $(24,2 \%)$ penduduk nagari bekerja di sektor pertanian dengan menggarap lebih dari 50 ha lahan pertanian. Jenis pertanian yang digeluti oleh masyarakat adalah tanaman holtikultura (sayuran, cabe, tomat, dan kacang-kacangan). Dengan kondisi seperti demikian, praktis hampir seluruh daratan Nagari Kotobaru ditanami dengan tanaman berwarna hijau yang mencirikan suasana khas pedesaan sepanjang musim. Sistem tanam yang digunakan oleh masyarakat juga tidak bergantung pada musim tanam, tetapi berlangsung sepanjang hari sesuai dengan musim tanaman yang diusahakan. Sehingga, setiap hari aktivitas mengolah lahan, menyemai dan menanam bibit, merawat tanaman, dan memanen dapat dijumpai.

Hasil pertanian penduduk dijual ke pasar yang dimiliki oleh nagari. Pasar nagari tersebut terletak persis di jantung nagari dan di pinggir jalan utama propinsi. Pasar beroperasi setiap hari Senin dan menyuplai berbagai jenis sayuran ke seluruh daearah di Sumatera Barat, termasuk Riau, Kepulauan Riau, dan Jambi. Berbagai jenis sayuran dijual oleh pedagang dari nagari-nagari di sekitar Kotobaru untuk kemudian dikirim dalam skala besar. Selain aktivitas jual beli, di pasar juga berlangsung proses pengepakan sayuran untuk dikirim ke berbagai kabupeten/kota di Sumbar dan propinsi luar Sumbar. Selain hari Senin, aktivitas pasar tidak berlangsung. Namun di pasar kios-kios milik pedagang tetap buka setiap hari. Mereka menjual berbagai kebutuhan harian, alat tulis, kebutuhan naik gunung, dan pakaian. Di pasar juga terdapat beberapa warung makan, penjual gorengan, dan jenis makanan lainnya yang berjualan setiap hari.

\section{Potensi Wisata Nagari Kotobaru}

Kegiatan pariwisata tak lain dan tak bukan adalah kegiatan pelesiran ke suatu tempat atau suasana berbeda dengan tempat dan suasana sehari-hari. Dalam bahasa lain, Salah Wahab secara panjang lebar mengatakan pariwisata mungkin saja hanya suatu gejala pengasingan diri (withdrawal symptom). Seseorang berusaha melepaskan dirinya dari lingkungan pekerjaan hariannya, suasana kebiasaan hidupnya atau hanya sekadar pergi nyepi ke tempat yang tenang untuk berkontemplasi mencari ilham (Wahab, 1989). Salah satu alasan kenapa suatu daerah dikunjungi wisatawan bisa mencakup keindahan alam, cagar alam, kebun raya, perkebunan, dan sawah ladang (Fandeli, 2001; 
Yoety, 2008b) yang dalam beberapa dekade terakhir akrab disebut dengan istilah ekowisata.

Dengan pertimbangan alasan orang melakukan wisata, Nagari Kotobaru, meskipun bukan daerah tujuan wisata memiliki potensi wisata yang dapat dikembangkan yang mencakup semua objek (alam, budaya, dan buatan) yang tidak memerlukan banyak penanganan agar dapat memberikan nilai daya tarik bagi wisatawan (Damanik \& Weber, 2006). Berikut akan diuraikan beberapa potensi yang dimiliki oleh Nagari Kotobaru yang dapat menunjang pengembangan pariwisata nagari.

\section{Talago (Telaga)}

Talago (telaga) ini berada di perbatasan antara Nagari Kotobaru dengan Nagari Batu Palano (Kabupaten Agam) berukuran $\pm 200 \times 350$ M memanjang mengikuti jalur lintas Padang-Bukittinggi. Telaga tersebut merupakan sumber irigasi dan pengairan enam nagari di sekitar dan dimanfaatkan oleh siapa saja untuk menanam daun anyaman tikar dengan aturan, penanam adalah pemilik daun anyaman yang ditanam tersebut. Hanya saja, status kepemilikan telaga masih belum jelas antara Nagari Kotobaru dan Batu Palano. Masing-masing nagari ini menyatakan telaga adalah bagian dari wilayah mereka dan oleh karenanya kondisi telaga tidak terawat. Kini, penyelesaian kasus perebutan sedang difasilitasi oleh pemerintah propinsi Sumatera Barat. Sebelumnya, telaga pernah digunakan sebagai objek wisata Sepeda Air yang dikelola oleh masyarakat dengan sistem sewa. Pengelola membuka kafe di pinggir telaga dan kemudian menyewakan sepeda air untuk pengunjung. Akan tetapi, sejak perselisihan kepemilikan dan tidak terawatnya telaga, wisata sepeda air sudah tidak lagi ada. Selain itu, beberapa kafe lama dan baru masih beroperasi di pinggiran telaga sepanjang jalan lintas. Aneka ragam makanan mereka jual dengan menyediakan view alam yang asri ke arah telaga dan tembus ke arah gunung Merapi.

\section{Perkebunan Holtikultura Masyarakat}

Mayoritas bumi Kotobaru adalah lahan pertanian holtikultura karena \pm 50 ha dari keseluruhan luas nagari diolah penduduk sebagai lahan pertanian holtikultura. Jenis tanaman yang mereka budidayakan adalah sayuran seperti cabe, tomat, kol, sawi, dan lain sebagainya. Sistem tanam petani Nagari Kotobaru tidak menggunakan pola musiman, tetapi petani menanam sepanjang tahun sesuai dengan masa perkembangan jenis tanaman yang dibudidayakan. Praktis setiap hari ditemui aktivitas menanam, merawat dan memanen yang dilakukan oleh petani. Para petani baik secara individu maupun berkelompok mengelola lahan dengan aktivitas mengolah lahan, bertanam bibit, merawat, dan panen setiap hari di lahan pertanian mereka. Disetiap kebun yang dikelola oleh petani terdapat pondok-pondok kecil tempat petani beristirahat dan menyimpan peralatan pertanian mereka. Beberapa pondok bahkan dihuni langsung oleh petani penggarap (mayoritas berasal dari Jawa Barat).

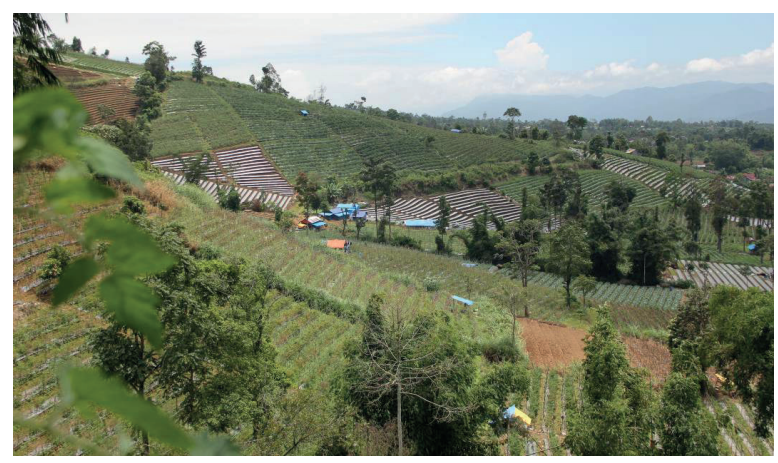

Gambar 1. Lahan Pertanian di Nagari

Kotabaru Sumber: Dokumentasi Penelitian, 2016

\section{Pintu Masuk dan Jalur Pendakian Gunung Merapi}

Belum ada catatan pasti tentang orang pertama dan asal mula pendakian ke Gunung Merapi dilakukan, tetapi beberapa catatan menyebutkan bahwa pendakian ke Gunung Merapi sudah dilakukan sebelum tahun 1980. Hingga saat ini, aktivitas pendakian berlangsung setiap hari. Jumlah pendaki akan lebih banyak pada akhir pekan atau musim liburan. Mayoritas mereka adalah anak muda dan pencinta alam. Nagari Kotobaru adalah pintu masuk satu-satunya ke gunung 
merapi. Para pendaki biasanya menggunakan kendaraan sampai ke tower pintu masuk di Jorong Subarang dan memulai pendakian dengan jalan kaki dari area parkir di tower yang merupakan batas akhir kendaraan roda empat dan roda dua. Jalan menuju persanggrahan pertama batas antara Nagari Kotobaru dan hutan lindung adalah milik nagari sepanjang \pm 1300 meter. Di kiri kanan jalan aktivitas pertanian berlangsung natural dengan mayoritas jenis tanaman cabe dan tomat.

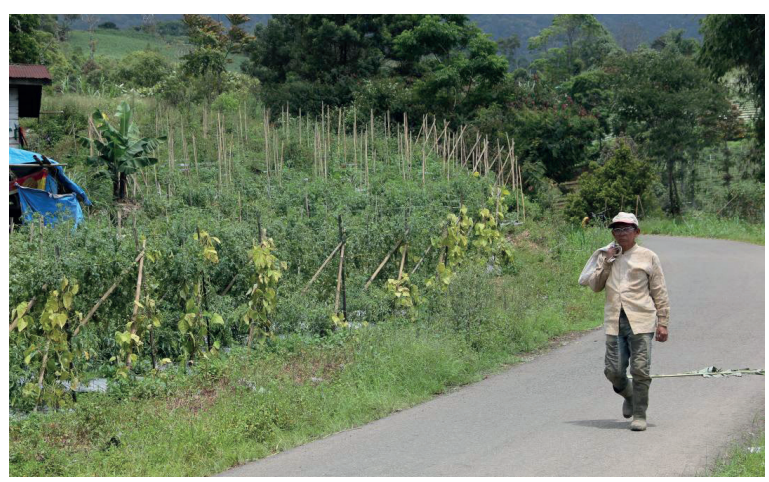

Gambar 2. Lahan Pertanian di Nagari Kotabaru Sumber: Dokumentasi Penelitian, 2016

\section{Rumah Rahasia Bung Hatta}

Di tengah masyarakat Nagari Kotobaru berkembang cerita bahwa Bung Hatta memiliki pondok rahasia di Nagari Kotobaru. Tempat tersebut bernama Amor Natura dan sering digunakan sebagai tempat rapat rahasia oleh Bung Hatta bersama kolega. Diperkirakan bangunan tersebut dibangun pada saat pusat pemerintahan berada di Kota Bukittinggi pada masa PDRI. Secara akademis, belum ada data yang akurat tentang cerita rumah persinggahan ini karena belum ada penelusuran yang lebih jauh tentang kebenaran dan detail cerita itu. Akan tetapi, pemerintah nagari merencanakan akan membangun prasasti di lokasi yang diduga tempat rapat rahasia Bung Hatta tersebut. Prasasti yang akan dibangun adalah dalam bentuk tertulis yang menceritakan tentang rumah rahasia itu. Tempat tersebut kemudian akan dinamai dengan pesanggrahan Bung Hatta. Rencana pembangunan tersebut sudah dituangkan dalam RPJM Nagari 20132015.

\section{Analisis Swot Ekowisata Nagari Kotobaru}

Konsep ekowisata, bagi sebagian kalangan masih tumpang tindih pengelompokannnya antara kategori pariwisata konvensional di satu sisi dan kategori wisata alternatif di sisi lain. Mieczkowski (1995) misalnya, menemukan kesulitan untuk menempatkan ekowisata dalam konteks wisata alternatif karena tidak bertepatan langsung dengan pariwisata budaya, tumpang tindih dengan pendidikan, ilmu pengetahuan, petualangan, dan bentuk-bentuk wisata agro yang baru-baru ini mencakup pro-poor tourism dan volunteer tourism (Wearing \& Neil, 2009). Walaupun pengelompokan itu masih tumpang tindih, Higham telah mengatakan bahwa ekowisata merupakan sub-kategori dari pariwisata berkelanjutan, oleh karenanya ia berkontribusi terhadap pembangunan berkelanjutan dan sustainability (Björk, 20017).Secara spesifik, Peter Björk mengatakan:

"ecotourism is related to nature, culture, farm, wildlife, and adventure tourism, and can be described as a sub-category of nature and culture tourism, a tourism form that can be practiced on farms or in wildlife, and consists of an adventurous nature (Björk, 20017).

Ekowisata pada dasarnya adalah perjalanan dan kunjungan yang bertanggung jawab terhadap alam lingkungan ke daerah alami. Perjalanan itu dengan tujuan menikmati dan menghargai alam yang dikelola dengan kaidah lokal dengan tujuan konservasi, pendidikan yang melibatkan masyarakat setempat dengan segala kaidah budaya yang mereka miliki (Arida, Baiquni, Janianton, \& Ahimsa-putra, 2014; Ghorbani, Raufirad, Rafiaani, \& Azadi, 2015; Latupapua, Pudyatmoko, Fandeli, \& Baiquni, 2015). Lingkungan yang asli senantiasa lebih menarik para wisatawan daripada yang tiruan (Wahab, 1989). Hal ini tidak lain karena kecenderungan manusia yang ingin keluar dari sekat keseharian mereka. Alam yang menjadi kekuatan ekowisata memberikan kepuasan batiniah bagi setiap orang dalam setiap perjalanan yang mereka lakukan. Kegiatan ekowisata lebih mengedepankan aspek alam 
ketimbang tiruan karena ekowisata mencakup aktivitas yang berkaitan dengan alam di mana wisatawan diajak melihat dan menyaksikan alam dari dekat, menikmati keasliannya, mempelajari, mengagumi keindahan alam, flora dan fauna termasuk aspek budaya sehingga membuatnya tergugah mencintai alam (Chirozva, 2015; Parker \& Khare, 2005; Pendit, 2006; Yoety, 2008b).

Untuk membahas potensi ekowisata di Nagari Kotobaru, penulis berpandangan bahwa ekowisata merupakan kegiatan wisata dengan objek utama keindahan alam tanpa

melakukan rekayasa apapun terhadap kondisi alam tersebut. Kemudian, pengelolaannya didasarkan pada partisipasi dan keikutsertaan masyarakat dengan tanpa merubah pola aktivitas dan perilaku hidup mereka sehari-hari, karena aktivitas dan perilaku hidup masyarakat setempat merupakan bagian dari aktivitas wisata alam. Dengan konsep ini, Nagari Kotobaru, sebagaimana diuraikan di atas dengan segala potensi yang dimiliki dinilai sangat berpeluang untuk dikembangkan menjadi kawasan ekowisata, tetapi juga terdapat kelemahan dan tantangan. Peluang dan tantangan tersebut dapat dilihat dalam tabel 2 :

Tabel 2.

Analisis SWOT Pengembangan Kawasan Ekowisata Nagari Kotobaru

\begin{tabular}{|c|c|c|}
\hline & Helpful & Harmful \\
\hline & Strengths (Kekuatan) & Weaknesses (Kelemahan) \\
\hline 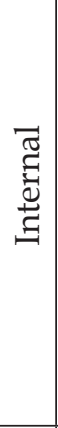 & $\begin{array}{l}\text { - Nagari telah mencantumkan sektor } \\
\text { pariwisata dalam RPJM } \\
\text { - Masyarakat sudah familiar dengan } \\
\text { kedatangan orang baru (wisatawan), } \\
\text { terutama pendaki Gunung Merapi. }\end{array}$ & $\begin{array}{l}\text { - Infrastruktur nagari untuk kepentingan } \\
\text { wisata belum lengkap } \\
\text { - Nagari belum memiliki SDM untuk } \\
\text { mengelola ekowisata } \\
\text { - Anggaran pengembangan wisata minim } \\
\text { - Belum ada kebijakan pengembangan wisata } \\
\text { untuk kawasan Kotobaru dan sekitar di } \\
\text { tingkat kabupaten dan propinsi } \\
\text { - Terdapat konflik interest dalam pengelolaan } \\
\text { pintu masuk Gunung Merapi }\end{array}$ \\
\hline & Oportunity (Peluang) & Threats (Ancaman) \\
\hline 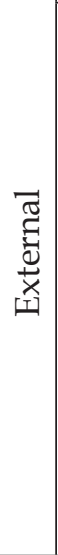 & $\begin{array}{l}\text { - Terletak di jalur utama propinsi Sumatera } \\
\text { Barat. } \\
\text { - Memiliki pasar agro penyuplai sayuran ke } \\
\text { Sumbar dan propinsi sekitar } \\
\text { - Memiliki lahan seluas } 5 \text { ha di pintu masuk } \\
\text { Gunung Merapi } \\
\text { - Pintu masuk satu-satunya untuk melakukan } \\
\text { pendakiaan ke Gunung Merapi } \\
\text { - Memiliki landscape dan panorama alam yang } \\
\text { asri dengan suhu rata-rata } 21^{0} \mathrm{C} \text { pada siang } \\
\text { hari } \\
\text { - Mayoritas lahan ( } \pm 50 \mathrm{Ha}) \text { dikelola sebagai } \\
\text { pertanian holtikultura }\end{array}$ & $\begin{array}{l}\text { - Terdapat objek wisata lain yang lokasi dan } \\
\text { letaknya berdekatan dengan Kotobaru }\end{array}$ \\
\hline
\end{tabular}

Sumber: Data Primer 2016

\section{Kekuatan}

Dalam standar manajemen pengembangan pariwisata, kekuatan Nagari Kotobaru masih minim. Sampai penelitian ini dilakukan, kekuatan itu baru sebatas kebijakan nagari yang dicantumkan secara tertulis dalam RPJM tentang pengembangan pariwisata. Selain kebijakan dari pemerintah nagari, yang menjadi kekuatan nagari lainnya bahwa masyarakat sekitar sudah familiar dan terbiasa dengan para pendaki gunung yang pada dasarnya adalah wisatawan. Mereka tidak canggung 
berinteraksi dengan mereka. Bahkan, sebagian pedagang di Pasar Kotobaru menyediakan khusus barang dagangan untuk kebutuhan para pendaki gunung.

\section{Peluang}

Meskipun kekuatan minim, Nagari Kotobaru memiliki peluang yang sangat banyak. Letak Nagari Kotobaru sangat strategis karena berada persis di jalur utama jalan lintas Sumatera, yaitu jalur Padang-Bukittinggi-Riau atau Sumatera Utara. Sebagai jalur perlintasan, Nagari Kotobaru menjadi etalase Kabupetan Tanah Datar di sisi timur yang memiliki Pasar Agro dengan fungsi sebagai penyuplai sayuran ke seluruh Sumbar, Riau, dan Kepulauan Riau. Nagarijuga memiliki tanah ulayat di perbatasan dengan hutan lindung yang merupakan pintu masuk pendakian ke Gunung Merapi. Asset tanah tersebut dapat dijadikan sebagai lokasi pengembangan kawasan ekowisata. Sampai penelitian ini dilakukan, lahan tersebut masih belum dikelola oleh nagari secara optimal. Lahan hanya disewakan kepada warga untuk dikelola menjadi ladang. Hal yang paling penting juga adalah, nagari telah menuangkan pengembangan wisata dalam RPJM Nagari.

Selain itu, Nagari Kotobaru memiliki alam yang asri dengan suhu rata-rata $21^{\circ} \mathrm{C}$ dan berbatasan langsung dengan hutan negara. Perbatasan tersebut merupakan pesanggrahan dan pintu masuk pendakian gunung Merapi. Sepanjang jalan pendakian gunung merapi, masyarakat mengelola lahan mereka dengan tanaman holtikultura yang menyumbang terhadap kehijauan dan keasrian lingkungan. Selain itu, landscape alam nagari tidak datar, tapi terdiri dari bukit-bukit landai memberikan pandangan ke berbagai sudut. Sehingga, baik Gunung Merapi maupun Gunung Singgalang dapat dinikmati dari Nagari Kotobaru. Hanya dengan sedikit naik ke lereng gunung Merapi di bagian timur nagari, pengunjung sudah dapat menikmati alam yang asri.

\section{Kelemahan}

Kelemahan utama Nagari Kotobaru dalam pengembangan kawasan ekowisata adalah belum lengkapnya infrastruktur penunjang. Infrastruktur tersebut terutama fasilitas jalan yang masih belum memadai menuju pesanggrahan di perbatasan hutan nagari dengan hutan negara. Infrastruktur lainnya adalah ketersediaan sarana layanan umum seperti MCK, transportasi untuk wisatawan serta penyediaan tempat parkir. Selain itu, kelemahan klasik anggaran juga menjadi masalah utama bagi nagari dalam mengembangkan kawasan wisata. Di luar itu, yang jauh lebih penting adalah ketersediaan Sumber Daya Manusia (SDM) yang memiliki kemampuan dalam merumuskan dan mengimplementasikan konsep ekowisata yang belum dimiliki oleh Nagari Kotobaru hingga saat penelitian dilakukan.

Kelemahan lainnya adalah terdapatnya konflik kepentingan dalam pengelolaan pintu masuk pendakian Gunung Merapi. Pengelolaan pintu masuk sekarang hanya dikuasai oleh oknum dan kelompok tertentu dan mengambil keuntungan untuk kepentingan sendiri dan belum menyumbang terhadap pendapatan nagari Kotobaru. Hal ini, membutuhkan pendekatan khusus untuk menyelesaikan agar tidak terjadi konflik (horizontal dan vertikal) di nagari.

\section{Ancaman}

Secara umum, tidak ada ancaman berarti terhadap pengembangan ekowisata Nagari Kotobaru. Ancaman terhadap pengembangan hanya kedekatan nagari Kotobaru dengan beberapa objek wisata di sekitar seperti objekobjek wisata di Kota Bukittinggi, wahana permainan (Minang Fantasi) di Padang Panjang, dan lain sebagainya. Akan tetapi, ancaman tersebut sekaligus akan bisa menjadi peluang jika nagari mampu menjalin kerjasama dengan mengintegrasikan kegiatan pariwisata dengan objek-objek wisata di sekitar

\section{Potensi Pengembangan Ekowista Nagari Kotobaru}

Berdasarkan analisis SWOT sebagaimana disajikan dan diuraikan dalam tabel 2, nagari Kotobaru memiliki potensi besar untuk dikembangkan sebagai kawasan ekowisata. Penilaian ini didasarkan atas pertimbangan 
lebih dominannya kekuatan dan peluang yang dimiliki oleh nagari untuk dikembangkan dibanding kelemahan dan tantangannya. Kelemahan dan tantangan yang ada dapat diatasi sejalan dengan proses pengembangan kawasan. Hal ini juga didasarkan pada hasil penelitian Haryanto yang merekomendasikan bahwa tipe pengelolaan pariwisata berbasis komunitas dalam bentuk Desa Wisata merupakan tipe pengelolaan pariwisata yang direkomendasikan sebagai Model Pengembangan Pariwisata Berkelanjutan yang merupakan bentuk implementasi dari konsep ekowisata (Haryanto, 2014). Nagari Kotobaru memiliki syarat-syarat untuk pengembangan ekowisata dengan mengacu pada analisa SWOT di atas.

Dalam proses pengembangan ekowisata, nagari Kotobaru dapat menggunakan ekowisata "tipe masyarakat" sebagaimana diperkenalkan oleh Arida, dkk (2014) dari hasil penelitiannya tentang dinamika ekowisata Tri Ning Tri di Bali. Menurut mereka, pola pengelolaan ekowisata "tipe masyarakat" ini dikelola sepenuhnya oleh masyarakat baik secara mandiri maupun dibantu pihak luar. Karakter khas pengelolaan wisata "tipe masyarakat" ini adalah keterlibatan masyarakat secara maksimal, berskala kecil (atraksi dan modal) dan berjejaring. Ciri paling menonjolnya adalah tingkat keterlibatan masyarakat yang tinggi (Arida et al., 2014). Dengan menggunakan pendekatan pengelolaan ekowisata "tipe masyarakat", Nagari Kotobaru hanya perlu menyesuaikan dan merencanakan pembangunan ekowisata sesuai dengan kondisi-kondisi alam, iklim, ekologi, dan budaya setempat. Aktivitas harian penduduk di ladang dapat menjadi atraksi wisata bagi pengunjung terutama bagi wisatawan yang berasal dari perkotaan. Kegiatan menanam bibit sayuran, memetik tomat dan cabe, menyiang lahan akan menjadi daya tarik tersendiri bagi kegiatan ekowisata nagari. Setiap pengunjung diberikan fasilitas seperti sepatu boat dan sarung tangan sebelum melakukan aktifitas pertanian. Kemudian bagi pengunjung yang berminat untuk bermalam (menginap) dapat difasilitasi dengan pondokpondok ladang petani dengan dilengkapi dengan fasilitas MCK dan peralatan tidur yang cukup. Selain aktivitas mengikuti kegiatan pertanian, kegiatan wisata yang juga dapat ditawarkan adalah naik ke Gunung Merapi.

Paket wisata yang ditawarkan didesain senatural mungkin dengan memanfaatkan landscape dan panorama alam nagari, dan kegiatan masyarakat di sektor pertanian holtikultura. Penyelenggaraannya dilakukan secara sederhana, yang menonjol adalah pemeliharaan keaslian lingkungan tanpa merusak alam, fauna, dan flora (Yoety, 2008b). Kegiatan wisata menyuguhkan keindahan alam dan aktivitas penduduk apa adanya dan membiarkan wisatawan menikmati perjalanan mereka tanpa direkayasa. Untuk menyempurnakan kepuasan pengunjung, perlengkapan harian yang biasa digunakan penduduk dalam melakukan aktivitas di ladang dapat dipinjamkan/disewakan kepada wisatawan.

Kegiatan berladang, menanam sayur, memetik sayur, memanen cabe, tomat, kacang, dan tanaman lain sebagaimana diuraikan dalam SWOT akan menjadi kegiatan yang bersifat edukatif bagi wisatawan. Apalagi kegiatan itu ditambahkan dengan mengemas paket tidur di pondok ladang dalam suhu yang dingin menggunakan selimut akan menjadi pengalaman baru bagi wisatawan. Dengan pengalaman itu wisatawan akan merasa lepas dari aktivitas rutin mereka. Kondisi seperti demikian sesungguhnya yang digambarkan dalam bahasa yang puitis oleh Salah Wahab dalam mendeskripsikan daya dorong kenapa orang melakukan kegiatan wisata:

....keadaan alam dan sosial yang baru dapat menggerakkan hatinya untuk berlaku berbeda dari kebiasaannya karena dia merasa bebas dari pembatasan dan hambatan yang biasa karena pola kehidupan rutin seharihari. Dia dapat meneropong dirinya sendiri dalam cahaya yang lain, dalam situasi nikmat yang lain, dalam pola tingkah laku yang lain yang pada waktu-waktu yang lalu dia mungkin belum mengenal dirinya sendiri.... (Wahab, 1989).

Ekowisata harus melibatkan masyarakat lokal, memberi dampak ekonomi bagi 
masyarakat lokal, meminimalisir kerusakan lingkungan, dan bermanfaat dalam pengembangan pendidikan (Hill \& Hill, 2011). Oleh karena itu, pelibatan masyarakat dalam pengelolaan ekowisata merupakan aspek penting dalam pengembangan ekowisata karena perencanaan dan pengembangan ekowisata hanya bisa dilakukan dengan melibatkan masyarakat sebagai sentral kegiatan (Chirozva, 2015; Parker \& Khare, 2005). Untuk itu, dalam pengelolaan ekowisata pengetahuan dan keterampilan masyarakat lokal perlu ditingkatkan.

Peningkatan pengetahuan dan keterampilan ini penting karena kadangkala masyarakat lokal tidak tahu peluang dan tantangan yang mereka miliki, sehingga menjadikan mereka tidak mampu bersaing dalam mengembangkan (Nepal, 2004). Dalam hal ini diperlukan keterlibatan pemerintah Kabupaten Tanah Datar dalam melakukan penguatan masyarakat dengan memberikan pelatihan dan pemberdayaan. Dalam melakukan pemberdayaan, pemerintah menempatkan diri sebagai fasilitator (Firdaus, 2016). Pemerintah juga dapat melibatkan kampus dan LSM dalam menyiapkan masyarakat nagari sebagai aktor utama dalam kegiatan ekowisata. Hal ini penting karena posisi masyarakat adalah aktor utama dalam pengembangan ekowisata.

\section{SIMPULAN}

Nagari Kotobaru adalah etalase Kabupaten Tanah Datar karena terletak persis di bagian paling luar Kabupaten Tanah Datar yang berbatasan dengan Kabupaten Agam. Letaknya juga sangat strategis karena menjadi lalu lintas Sumatera rute Padang - Riau \& Sumatera Utara. Selain letaknya yang strategis, Nagari Kotobaru memiliki alam yang asri di antara Gunung Merapi dan Gunung Singgalang. Keindahan itu didukung oleh aktivitas masyarakat yang dominan bekerja sebagai petani holtikultura. Tidak hanya itu, Nagari Kotobaru sekaligus juga adalah pintu masuk para pencinta alam untuk menaiki Gunung Merapi. Dengan letaknya yang strategis, alamnya yang indah, dan fungsinya sebagai pintu masuk ke Gunung Merapi, Nagari Kotobaru memiliki potensi yang besar untuk dikembangkan sebagai kawasan ekowisata yang mengutamakan keindahan alam sebagai objek.

Berdasarkan analisis SWOT terhadap potensi-potensi yang dimiliki oleh Nagari Kotobaru untuk dikembangkan menjadi kawasan ekowisata, maka pola ekowisata yang cocok dikembangkan di Nagari Kotobaru adalah ekowisata tipe masyarakat. Ekowisata tipe masyarakat adalah kegiatan ekowisata yang mengutamakan keterlibatan masyarakat lokal dalam pengelolaannya. Dalam prakteknya, pengelolaan ekowisata tipe masyarakat ini akan sangat bergantung dengan penegatahuan, keterampilan, dan kesiapan masyarakat lokal untuk mengelolanya. Sehingga dengan demikian, dibutuhkan masyarakat sadar wisata. Akan tetapi, sejauh ini belum ada kegiatan yang dilakukan baik oleh pemerintah maupun swasta terhadap masyarakat guna mengembangkan kegiatan ekowisata. Hal inilah ke depan yang perlu dilakukan untuk menjadikan Nagari Kotobaru sebagai Nagari Ekowisata sebagaimana dituangkan dalam RPJM Nagari Kotobaru.

\section{UCAPAN TERIMA KASIH}

Artikel ini bagian dari hasil penelitian hibah DRPM Ristek DIKTI pada skema penelitian dosen pemula. Penelitian didanai sesuai dengan Surat Perjanjian No. 010/ SP2H/LT/DRPM/2016, tanggal 17 Februari 2016. Penulis mengucapkan terima kasih kepada DRPM UP3M STKIP PGRI Sumatera Barat yang telah menfasilitasi penulis untuk mengakses hibah penelitian ini. Di lapangan, penulis berterimakasih kepada masyarakat dan pemerintah Nagari Kotobaru yang telah memberikan informasi dan data untuk penelitian. Kepada kolega di Prodi Pendidikan Sosiologi STKIP PGRI Sumatera Barat, Bapak Faishal Yasin, M. Pd yang telah membantu proses penelitian lapangan, penulis mengucapkan terima kasih secara khusus.

\section{DAFTAR PUSTAKA}

Abya, H., Khalili, M. M. N., Ebrahimi, M., \& Movahed, A. (2015). Strategic Planning for Tourism Industry Using 
SWOT and QSPM. Management Science Letters, 5, 295-300. http:// doi.org/10.5267/j.msl.2015.1.009.

Arida, I. N. S., Baiquni, M., Janianton, D., \& Ahimsa-putra, H. S. (2014). Dinamika Ekowisata Tri Ning di Bali: Problematika dan Strategi Pengembangan Tiga Tipe Ekowisata di Bali. Kawistara, 4(2), 111-127.

Björk, P. (20017). Defenition Paradoxes; From Concept to Defenition. In J. Higham (Ed.), Critical Issues in Ecotourism: Understanding a Complex Tourism Phenomenon (pp. 23-45). Elsevier Ltd.

BPS. (2016). Laporan Bulanan Data Sosial Ekonomi.

Chirozva, C. (2015). Community Agency and Entrepreneurship in Ecotourism Planning and Development in The Great Limpopo Transfrontier Conservation Area. Journal of Ecotourism, 14(2-3), 185-203. http:/ / doi.org/10.1080/14724049.2015.104 1967.

Damanik, J., \& Weber, H. F. (2006). Perencanaan Ekowisata; Dari Teori ke Aplikasi. Yogyakarta: Andi.

Fandeli, C. (2001). Dasar-Dasar Manajemen Kepariwisataan Alam. Yogyakarta: Liberty.

Firdaus, F. (2016). Evaluasi Proyek Pembangunan Sosial Pada Kelompok Masyarakat Kawasan Hutan Mbeliling, Kab. Manggarai Barat, NTT. Jurnal Ilmu Sosial Mamangan, 5(1), 13-22.

Ghorbani, A., Raufirad, V., Rafiaani, P., \& Azadi, H. (2015). Ecotourism Sustainable Development Strategies Using SWOT and QSPM Model: A Case Study of Kaji Namakzar Wetland, South Khorasan Province, Iran. Tourism Management Perspectives, 16, 290-297. http:/ / doi. org/10.1016/j.tmp.2015.09.005.

Haryanto, J. T. (2014). Model Pengembangan Ekowisata Dalam Mendukung
Kemandirian Ekonomi Daerah; Studi Kasus Provinsi DIY. Kawistara, 4(3), 271-286.

Hijriati, E., \& Mardiana, R. (2014). Pengaruh Ekowisata Bebasis Masyarakat Terhadap Perubahan Kondisi Ekologi, Sosial, dan Ekonomi di Kampung Batusuhunan, Sukabumi. Solidity: Jurnal Sosiologi Pedesaan, 2(3), 146-159.

Hill, J. L., \& Hill, R. A. (2011). Ecotourism in Amazonian Peru : Uniting Tourism, Conservation and Community Development. Geography, 96(2), 7585.

Kementrian Pariwisata. (2015). Laporan Kinerja Kementerian Pariwisata 2014. Jakarta.

Kurniawati, R. (2013). Modul pariwisata berkelanjutan.

Latupapua, Y. T., Pudyatmoko, S., Fandeli, C., \& Baiquni, M. (2015). Ritual Sebagai Daya Tarik Ekowisata Di Desa Nounea Kabupaten Maluku Tengah. Kawistara, 5(3), 221-328.

Miles, M. B., \& Huberman, A. M. (1992). Analisis Data Kualitatif: Buku Sumber Tentang Metode-Metode Baru. Jakarta.: UI Press.

Nepal, S. K. (2004). Indegenous Ecoturism in Central British Columbia: The Potential for Building Capacity in The

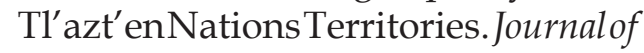
Ecotourism, 3(3), 173-194. http:/ / doi. org/10.1080/14664200508668431.

Parker, S., \& Khare, A. (2005). Understanding Success Factors for Ensuring Sustainability in Ecotourism Development in Southern Africa. JournalofEcotourism,4(1),32-46.http:/ / doi.org/10.1080/14724040508668436.

Pendit, N. S. (2006). Ilmu Pariwisata; Sebuah Pengantar Perdana. Jakarta: Pradnya Paramita.

Picard, M. (2005). Bali: Pariwisata Budaya dan Budaya Pariwisata. Jakarta: Gramedia. 
Pitana, I. G., \& Gayatri, P. G. (2005). Sosiologi Pariwisata. Yogyakarta: Andi.

Spillane, J. J. (1987). Ekonomi Pariwisata, Sejarah dan Prospeknya. Yogyakarta: Kanisius.

Sudarmadji, \& Darmanto, D. (2014). Dampak Lingkungan dan Risiko Bencana Pengembangan Desa Wisata; Studi Kasus di Desa Wisata Sambi. Kawistara, 4(2), 111-224.

Syamsuridjal, D., \& Kaelany, H. (1996). Peluang di Bidang Pariwisata. Jakarta: PT. Mutiara Sumber Widya.
Wahab, S. (1989). Manajemen Kepariwisataan. Jakarta: Pradnya Paramita.

Wearing, S., \& Neil, J. (2009). Ecotourism: Impacts, Potentials and Possibilities? (second). elsevier Ltd.

Yoety, O. A. (2006). Pariwisata Budaya: Masalah dan Solusinya. Jakarta: PT. Pradnya Paramita.

Yoety, O. A. (2008a). Ekonomi Pariwisata; Introduksi, Informasi dan Implementasi. Jakarta: Penerbit Buku Kompas.

Yoety, O. A. (2008b). Perencanaan dan Pengembangan Pariwisata. Jakarta: Pradnya Paramita. 